\title{
An unusual presentation of 17alpha hydroxylase deficiency
}

Authors: Florian Wernig ${ }^{1}$, Maura Moriarty ${ }^{1}$, Jeannie Todd ${ }^{1}$, Francis Lam ${ }^{1}$, Gill Rumsby ${ }^{1}$ 1 Dept of Endocrinology, Imperial College Healthcare NHS Trust, London

\section{Case History}

- 26 year old Afghani female

- Parents - consanguineous relationship

- Family Hx otherwise unremarkable

- Primary amennorhoea age 14

Normal breast development Reduced body hair

- Lost to medical follow up

- Spontaneous menarche age 18 Regular menstrual cycle

- Represented for investigation of 3 year $\mathrm{hx}$ Primary Infertility age 24

\begin{tabular}{|c|c|}
\hline \multicolumn{2}{|c|}{ Investigations: } \\
\hline Blood Pressure & Normal \\
\hline U\&E & Unremarkable \\
\hline Cortisol & $35 \mathrm{nmol} / \mathrm{L}$ \\
\hline $17-$ OHP & $2.1 \mathrm{nmol} / \mathrm{L}(<9.6)$ \\
\hline Short Synacthen Test & Peak Cortisol $139 \mathrm{nmol} / \mathrm{L}$ \\
& No rise in $17-\mathrm{OHP}$ \\
\hline DHEAS & $<0.4 \mu \mathrm{mol} / \mathrm{L}(0.7-11.5)$ \\
\hline Testosterone & $<0.5 \mathrm{nmol} / \mathrm{L}(<2.0)$ \\
\hline Oestradiol & $325 \mathrm{pmol} / \mathrm{L}$ \\
\hline $17-O H P$ & $2.1 \mathrm{nmol} / \mathrm{L}(<9.6)$ \\
\hline LH & $5.4 \mathrm{IU} / \mathrm{L}$ \\
\hline FSH & $6.7 \mathrm{IU} / \mathrm{L}$ \\
\hline Renin & $2.3 \mathrm{nmol} / \mathrm{L}(0.5-3.1)$ \\
\hline Aldosterone & $<60 \mathrm{pmol} / \mathrm{L}(90-700)$ \\
\hline
\end{tabular}

24 hour Urine Steroid Profile
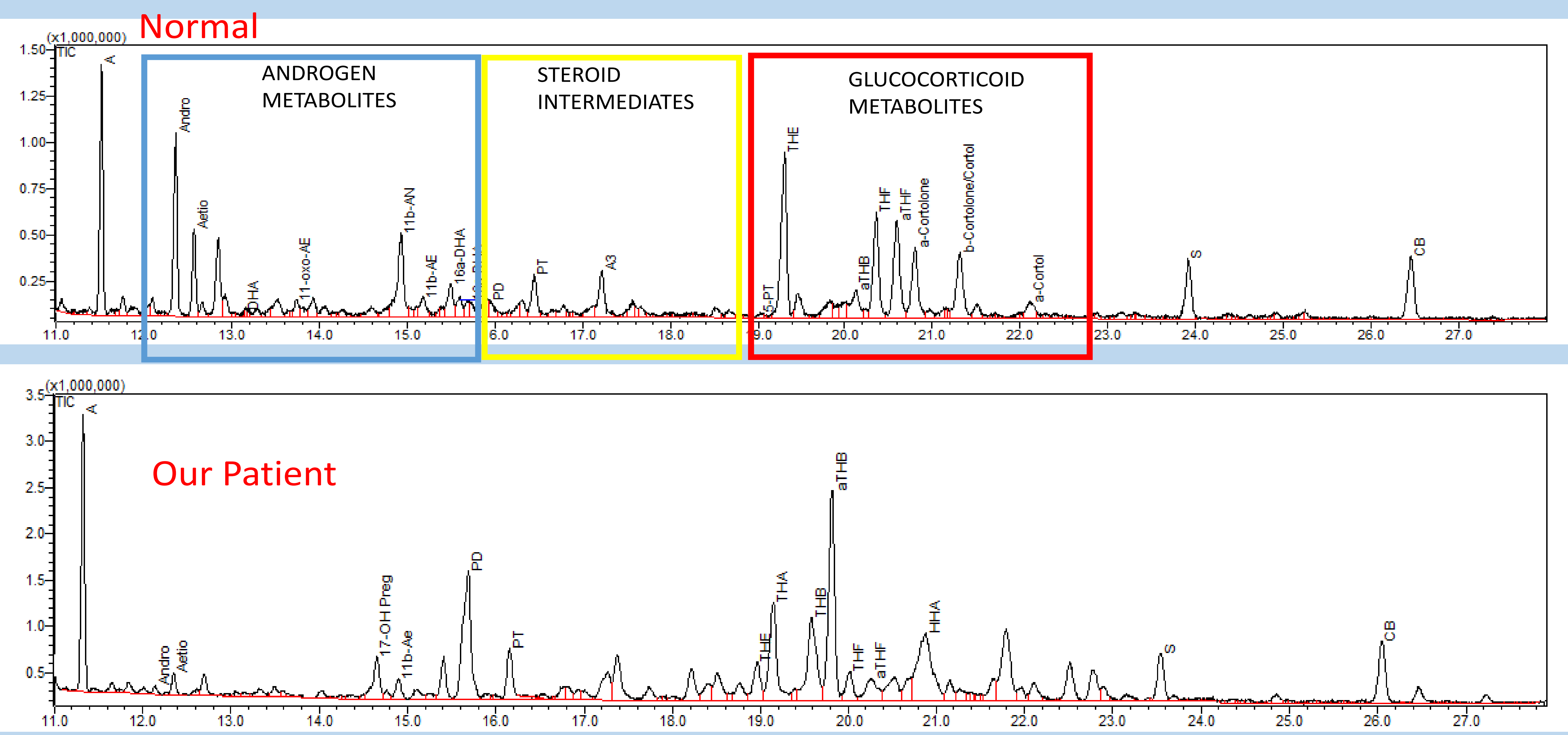

Urine Steroid Profile Result

- Decreased cortisol metabolites

- Raised Corticosterone and progesterone

- Increase in 17hydroxyprogesterone metabolites

Suggestive of partial 17 hydroxylase deficiency and 17,20 lyase deficiency

Aldosterone metabolites absent

- Raises added possibility of aldosterone synthase deficiency

\section{Clinical Course}

Commenced on prednisolone $3 \mathrm{mg}$ daily

- No change in sense of well being

IVF commenced

- Previous attempts at induced ovulation unsuccessful

- Ovarian stimulation (with gonadotrophins) and oocyte retrieval

- First cycle unsuccessful
- Genetic testing showed confirmed a 3 bp deletion ( $p$. Phe54del)This is reported to have approx. $37 \%$ of normal activity of 17 hydroxylase

- Activity of 17,20 lyase is estimated at $8 \%$ of normal

- Aldosterone synthase genetic testing was negative

17 alpha hydroxylase deficiency accounts for less than $1 \%$ of all patients diagnosed with congenital adrenal hyperplasia.

Almost 100 mutations in the CYP17A1 gene causing 17-hydroxylase/17,20-lyase deficiency (17OHD) have been described. CYP17A1 is expressed in both the adrenals and gonads. Hallmarks of 17OHD include hypertension, hypokalaemia, primary amenorrhoea and absence of secondary sexual characteristics. Clinical characteristics vary depending on the activity levels of 17 hydroxylase. Most patients with 17OHD remain infertile.

Given the low estimated 17,20 lyase activity levels a more severe clinical presentation would have been expected. The urine steroid profile suggests an additional aldosterone synthase deficiency in this patient and is the most likely reason for the absence of the classical features of hypertension and hypokalaemia. This has not been identified on genetic testing but the possibility of an alternative mutation exists.

\section{Discussion:}

What, if any, options are available for this lady to assist fertility?

Is there a role for long term steroid replacement? If yes, what is the most appropriate option in her case

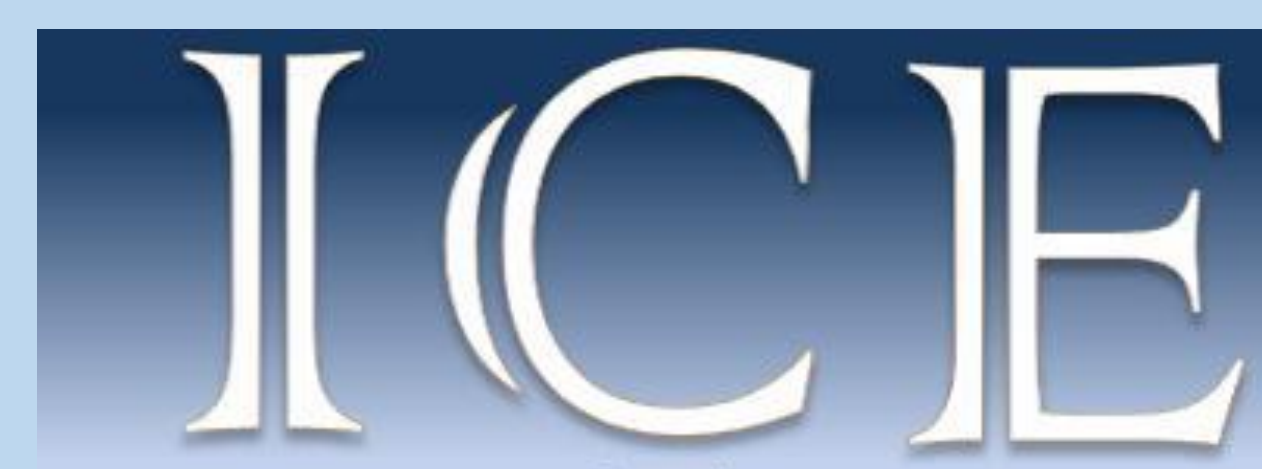

Imperial Centre for Endocrinology 